\title{
Performance of Manganese and Antimony co-doping Tin Dioxide Anodes Prepared at Different Temperatures
}

\author{
Cairu Shao ${ }^{1, *}$, Hongxing Ma ${ }^{1}$, Jianhua Zhang ${ }^{1}$, Yusi Jiang ${ }^{1}$, Huayue Cheng ${ }^{1}$, Xia Li $^{2}$ and Kaigui Zhu ${ }^{2}$ \\ ${ }^{1}$ Guangdong Research Institute of Rare-Metal, Guangzhou 510651, PR China \\ ${ }^{2}$ Department of physics, Beihang University, Beijing 100191, PR China. \\ *E-mail: shaocairu@,163.com
}

doi: $10.20964 / 2019.01 .25$

Received: 6 August 2018 / Accepted: 27 September 2018 / Published: 30 November 2018

In this article, the titanium based $\mathrm{Mn}-\mathrm{Sb}$ co-doping $\mathrm{SnO}_{2}$ anodes $\left(\mathrm{Ti} / \mathrm{Mn}-\mathrm{Sb}-\mathrm{SnO}_{2}\right)$ prepared by the coating pyrolysis method at different annealing temperatures were investigated. The novel Ti/Mn-Sb$\mathrm{SnO}_{2}$ anodes did not only perform higher stability than the Ti/ $\mathrm{Sb}-\mathrm{SnO}_{2}$ without $\mathrm{Mn}$ doping, but also exhibit superior capability of degrading phenol. The electrodes were characterized by X-ray diffraction (XRD), scanning electron microscopy (SEM) with energy dispersive X-Ray (EDX), polarization curve, chronopotentiometry, and phenol degradation simulation. Among all the samples, the Ti/Mn-Sb-SnO${ }_{2}$ electrode annealed at $550{ }^{\circ} \mathrm{C}$ performed the best catalytic stability. Moreover, the phenol removal efficiency of Ti/Mn-Sb-SnO 2 anode made at $600{ }^{\circ} \mathrm{C}$ almost reached $100 \%$ in $2 \mathrm{~h}$. To probe into the deep reason resulting in the better catalysis, the fluorescence spectrum method was applied to test the hydroxyl radicals produced on the surfaces of each electrodes in phenol oxidation. The results confirmed Mndoping could promote the catalysis activities of $\mathrm{Ti} / \mathrm{Mn}-\mathrm{Sb}-\mathrm{SnO}_{2}$ electrodes.

Keywords: Dimensionally stable anodes; Antimony doped tin dioxide; Manganese; phenol degradation.

\section{FULL TEXT}

(C) 2019 The Authors. Published by ESG (www.electrochemsci.org). This article is an open access article distributed under the terms and conditions of the Creative Commons Attribution license (http://creativecommons.org/licenses/by/4.0/). 